EDUCATION
PSYCHOLOGY

$1+D+i$

\section{Electronic Journal of Research}

in Educational Psychology

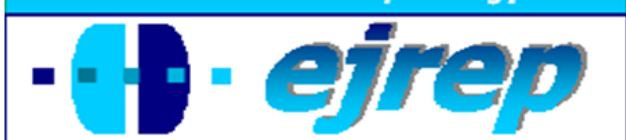

\title{
Cognitive Load Theory: An Empirical Study of Anxiety and Task Performance in Language Learning
}

\author{
I-Jung Chen ${ }^{1}$, Chi-Cheng Chang ${ }^{2}$ \\ ${ }^{1}$ Instructor, Dept. of Applied Foreign Languages, Takming University of \\ Science Technology, Taipei \\ ${ }^{2}$ Professor, Dept. of Technology Application \& Human Resources \\ Development, National Taiwan Normal University, Taipei
}

\section{Taiwan}

Correspondence: I-Jung Chen . Takming University of Science and Technology. No.56, Sec.1, Huanshan Rd., Taipei. Taiwan. E-mail: ijungchen@gmail.com

(C) Education \& Psychology I+D+i and Editorial EOS (Spain) 


\begin{abstract}
Introduction. This study explores the relationship among three variables - cognitive load, foreign language anxiety, and task performance. Cognitive load refers to the load imposed on working memory while performing a particular task. The authors hypothesized that anxiety consumes the resources of working memory, leaving less capacity for cognitive activities, and impeding effectiveness.
\end{abstract}

Method. The participants were 88 non-English major students enrolled in a 4-year program at a technical university in Taiwan. The Foreign Language Classroom Anxiety Scale was employed to examine their anxiety levels; the Cognitive Load Subject Rating Scale was utilized to measure their cognitive load while engaging in an English listening comprehension task.

Results. The students with higher foreign language anxiety also incurred a higher cognitive load. Foreign language anxiety and cognitive load were in negative correlation with listening comprehension.

Discussion. Learners who experience more anxiety incur a heavier cognitive load and receive lower test scores. To enhance learning effectiveness, instructors are encouraged to identify anxiety-provoking situations and provide a supportive learning environment so that the learners can devote their complete working memory resources to the learning tasks.

Keywords: cognitive load; cognitive load subject rating scale; foreign language anxiety; foreign language classroom anxiety scale; listening comprehension.

Received: 06/16/09 Initial Acceptance: 06/17/09 Definitive Acceptance: 07/06/09 


\section{Teoría de Carga Cognitiva: un estudio empírico de la an- siedad y la ejecución de tareas en el aprendizaje de idiomas}

\section{Resumen}

Introducción. Este estudio explora la relación entre tres varialbes: carga cognitiva, ansiedad hacia la lengua extranjera y, ejecución de la tarea. La carga cognitiva hace referencia a la carga impuesta a la memoria de trabajo cuando se está realizado una tarea específica. Los autores hipotetizaron que la ansiedad resta recursos a la memoria de trabajo, dejando una menor capacidad para las actividades cognitivas, e impidiendo así la eficacia.

Método. Los participantes fueron 88 estudiantes especializados no ingleses integrados en el cuarto año de enseñanza en una universidad técnica de Taiwan. La Escala de Ansiedad en el Aula de Lengua Extranjera fue utilizada para evaluar sus niveles de ansiedad; La Escala de Evaluación de la Carga Cognitiva Personal fue utilizada para medir la carga cognitiva mientras realizaban una tarea de comprensión oral en inglés.

Resultados. Los estudiantes con mayor ansiedad hacia la lengua extranjera también incurrían una mayor carga cognitiva. La ansiedad hacia la lengua extranjera y la carga cognitiva presentaban una correlación negativa con la comprensión oral.

Discusión. Los aprendizes que sufrían más ansiedad incurrían en una mayor carga cognitiva y recibían menos puntuación en los test. Para aumentar la eficacia del aprendizaje, se animó a los instructores a identificar situaciones que provocasen ansiedad y proporcionar un clima de aprendizaje de apoyo que permitiese a los aprendices dedicar por completo los recursos de la memoria de trabajo a las tareas de aprendizaje.

Palabras Clave: carga cognitiva; escala de valoración de la carga cognitive personal; ansiedad hacia lenguas extranjeras; escala de ansiedad en el aula de lengua extranjera; comprensión oral.

Recibido: 16/06/09 Aceptación inicial: 17/06/09 Aceptación final: 06/07/09 


\section{Introduction}

One of the primary objectives of instructional design is to facilitate student learning. Two of the key factors that often reported as impeding learning performance are memory overload and learning anxiety. Research on the overloading of the cognitive process has been conducted under the framework of the "cognitive load theory," which is an instructional theory based on our knowledge of human cognitive architecture that specifically addresses the limitations of working memory (Mayer, 2005). Meanwhile, anxiety refers to the subjective feelings of tension, apprehension, nervousness, and worry associated with an arousal of the autonomic nervous system (Horwitz, Horwitz, \& Cope, 1986). The detrimental effects of these two factors have been extensively studied with respect to different subjects and in various contexts (Osborne, 2006). According to Eysenck (1992), anxiety inhibits performance because working memory is occupied with worry rather than with task-focused thoughts. The purpose of the present study is, therefore, to explore the relationship between learning anxiety and memory load in the cognitive process so as to extend the studies regarding cognitive load theory to the affective factors.

The present study was conducted in the context of foreign language learning because anxiety is often reported as one of the important negative factors that causes poor language learning (Horwitz, 2001). The anxiety that arises when an individual is dealing with a foreign language is specified as foreign language (FL) anxiety (Horwitz, et al., 1986). The authors of the present study designed an empirical study employing a listening comprehension task to investigate the relationship between the cognitive load and FL anxiety. We hypothesized that the students with higher levels of FL anxiety would also experience higher levels of cognitive load while engaging in the foreign language listening comprehension tasks. This study progressed from a review of the literature on cognitive load theory and FL anxiety to an experiment examining the potential relationship between these two variables. Suggestions according to the research findings were provided.

\section{Cognitive Load Theory}

Based on our knowledge of the human cognitive architecture, cognitive load theory (CLT) addresses the limitations of working memory capacity and the construction of schema automation in long-term memory (Sweller, 2005). When dealing with novel information, working memory serves as temporary storage for and enables processing of information ne- 
cessary for performing complex cognitive tasks (Baddeley, 1992). In spite of the importance of the simultaneous functioning of information storage and processing, the capacity and duration of working memory is extremely limited. Miller (1956) suggested that working memory can only hold seven items of information at a time. Peterson \& Peterson (1959) found that incoming information is only retained in our working memory for approximately 20 minutes, if it is not repeated or memorized.

Contrary to the extremely limited capacity of working memory, long-term memory has an unlimited ability for conducting human cognitive activities and can be used to store schemas of varying degrees of automaticity. Schemas are cognitive constructs that incorporate multiple elements of information into a single element in the manner in which they will be used (Paas, Renkl, \& Sweller, 2003). Intellectual skill is derived from such a construction of large numbers of increasingly sophisticated schemas, each with a high degree of automaticity (Sweller, Van Merrienboer, \& Paas, 1998). Therefore, the ultimate goal of learning is to store new information in the long-term memory in the form of schemas and to perform schema automation (Merriënboer \& Sweller, 2005; Sweller, Merriënboer, \& Paas, 1998).

However, before incoming information is stored in the long-term memory, it must be processed through working memory first. Overloading working memory impedes this information processing operation and leads to ineffective learning. The educational application of CLT hence mainly focuses on the reduction of workload on working memory so as to increase learning effectiveness.

\section{Types of Cognitive Load}

Cognitive load refers to the total amount of mental activity performed by working memory at any point in time (Cooper, 1998). There are three kinds of cognitive load: intrinsic, extraneous, and germane (Paas, et al., 2003; Sweller, 2007). Intrinsic cognitive load arises from the nature of an incoming stimulus. In other words, intrinsic cognitive load cannot be altered by instructional interventions because the element interactivity is intrinsic. Extraneous cognitive load is, on the other hand, generated by instructional interventions. An inappropriate instructional design that requires a considerable amount of working memory resources may impose a heavy cognitive load and thus interferes with learning. Extraneous cognitive load is undesirable and can be controlled by the instructor. The third and desired type of cognitive load is germane cognitive load, which occurs when working memory resources are engaged in 
learning and the construction of schema automation. This process is essential to learning and is also under the control of the instructor. The three cognitive loads are additive. Effective learning therefore can be achieved by reducing extraneous cognitive load as far as possible and allowing the freed working memory resources to be devoted to germane cognitive load (Sweller, 2007). Over the past two decades, CLT has been used as a framework for designing instructional procedures and materials for complex learning, with the intention of reducing extraneous cognitive load and increasing germane cognitive load.

\section{Foreign Language Anxiety}

During language learning, affective filters (Krashen, 1988) have been acknowledged for its effects. Among the affective variables, anxiety stands out as one of the most influential factors, which affects learners at every stage of learning, whether during input, processing, or performance (MacIntyre \& Gardner, 1989). Anxiety is the subjective feeling of tension, apprehension, nervousness, and worry associated with an arousal of the autonomic nervous system (Horwitz, et al., 1986). MacIntyre \& Gardner (1989) proposed that anxiety leads to deficits in learning and performance. In later research, they corroborated that anxiety-arousal interferes with a learner's cognitive ability to absorb, process, and produce a foreign language (MacIntyre \& Gardner, 1991a, 1991b; MacIntyre \& Gardner, 1994a, 1994b).

Anxiety occurring in a foreign-language learning situation is referred to as foreign language anxiety (FL anxiety), which has been defined by Horwitz, et al. (1986) as "a distinct complex of self-perceptions, beliefs, feelings, and behaviors related to classroom language learning arising from the uniqueness of the language learning process." According to this definition, individuals may feel a threat to their self-image because they have to engage in tasks in the foreign language over which they have a poor command. Results of the recent research indicated that anxiety was often reported to be an important cause for decreased learning motivation, interference with the learning process, and poor performance (Elkhafaifi, 2005; Pappamihiel, 2002; Sparks \& Ganschow, 2007).

While CLT deals with the load imposed on the cognitive system and its impact on learning effectiveness, FL anxiety is also a factor proved to have a significant influence on learning outcomes. Eysenck (1992) proposed that the performance deficits often associated with elevated levels of anxiety reflect an underlying limitation in the functional capacity of working memory. In this regard, it is worthwhile to explore the potential relationship between 
cognitive load and FL anxiety. Does a learner with a higher level of FL anxiety incur a higher cognitive load in the learning process as well? In addition, Bratfish, Borg, \& Dornic (1972) claimed that the perceived difficulty of any given activity would play a decisive role in determining a person's feelings, attitudes, motivation, etc., concerning that activity. Since the degree of the cognitive load and anxiety varies person by person, the present study also investigated the correlation between a learner's perceived difficulty and the two variables, cognitive load and FL anxiety.

\section{Listening comprehension in foreign language learning}

Although CLT has been extensively discussed in relation to instructional material design, empirical studies on the relationship between cognitive load and other affective factors in the language domain such as FL anxiety are still few in number. The present study aimed to contribute to our understanding of FL anxiety in relation with cognitive load. The learning task students conducted in this study was an English listening comprehension test, because Horwitz, et al. (1986) suggested that FL anxiety is most closely associated with listening and speaking tasks. Listening comprehension is perceived to be particularly difficult and often causes anxiety for foreign language learners since the relaying of the message is an ongoing process that learners must comprehend and listen to simultaneously (Goh, 2000; Kao, 2006; Tercanlioglu, 2005). While listening, the message moves along a time axis, and usually the listener has no control over the speech rate nor has the chance to review the message. Based on our knowledge of the information process, to capture spoken information, listeners must 1) comprehend the content as they listen to it, 2) retain information in their working memory, 3) integrate it with what follows, and 4) continually adjust their understanding of what they hear in light of prior knowledge and incoming information (Osada, 2004). This complex process of listening comprehension imposes a heavy cognitive load on working memory. The findings of the present research will not only shed new light on the reduction of extraneous cognitive load but also on the decrease of FL anxiety and ultimately on the enhancement of learning effectiveness.

\section{Research Questions}

This study explores the relationship among FL anxiety, cognitive load, and listening comprehension performance. Information concerning students' linguistic abilities and perceived difficulty of foreign language comprehension were also investigated. Specifically, the 
study addressed the following questions:

1. Does the listening comprehension performance of a foreign language correlate with the levels of FL anxiety and cognitive load?

2. Does the levels of FL anxiety correlate with a learner's cognitive load while engaging in a foreign language listening comprehension task?

3. Do the levels of cognitive load, FL anxiety, and performance differ across different levels of linguistic ability and perceived difficulty in listening comprehension?

\section{Method}

\section{Participants}

The participants of the study consisted of 88 non-English major students enrolled in a four-year program at a technology university in northern Taiwan. There were 20 male students and 68 female students. Of the participants, 37 were from level A and 51 were from level B. Their ability levels were measured by the placement test that the school conducted at the beginning of each academic year to judge English proficiency. Level A is considered as lower intermediate and level B as higher elementary. There are four levels in all, the remaining being level $\mathrm{C}$ for elementary and level $\mathrm{D}$ for beginners. The subjects ranged from 18 to 22 years of age. All had previously undergone six years of English instruction in high school.

\section{Instruments}

The Foreign Language Classroom Anxiety Scale (FLCAS) (Horwitz, et al., 1986) and the Cognitive Load Subjective Rating Scale (CLSRS) (Paas, Van Merriënboer, \& Adam, 1994) were used in the study. The FLCAS consisted of 33 items. For each item, the participants answered on a 5-point Likert scale ranging from 5 points, representing "strongly agree," to 1 point, representing "strongly disagree." Higher scores indicated higher anxiety levels and lower scores indicated lower anxiety levels. The estimated reliability of the FLCAS (Cronbach's $\alpha)$ was $.87(\mathrm{n}=88)$, indicating that the internal consistence among items was adequate. In the case of the CLSRS, the participants were asked to estimate how much mental effort they invested when undertaking a listening test on a 7-point scale ranging from "extremely low," corresponding to the number 1, to "extremely high," corresponding to the number 7 . The scores obtained from this rating scale were used as an indicator of cognitive load. The higher the score represented the higher the estimated cognitive load on mental effort. Based on the reliability and sensitivity of these tests, the subjective ratings proved to be useful in 
instructional research (Paas, et al., 1994). The CLSRS had a high internal reliability, achieving an $\alpha$ coefficient of $.915(\mathrm{n}=88)$.

In addition, the participants were asked to rate their perception of the difficulty of English listening comprehension in general rather than just the specific test used for the study. They were asked to rate the tasks as easy, medium, or difficult. All of the questions were translated into Mandarin Chinese to facilitate the students' comprehension.

Finally, for the study's English comprehension task, the authors employed a listening comprehension test extracted from the intermediate-level GEPT (General English Proficiency Test). The GEPT is a public English testing system designed and administered by the LTTC (Language Training \& Testing Center) and supervised by the Ministry of Education in Taiwan. The LTTC GEPT has five levels (elementary, intermediate, high-intermediate, advanced, and superior) and includes listening, reading, writing, and speaking components. According to CLT, the levels of extraneous cognitive load may have little significance if the intrinsic cognitive load or the task's complexity are low, because there may be sufficient working memory resources available to learn (Sweller, 2007). With the intention of inducing the desired cognitive load, the study used the intermediate level test, which is considered as challenging to the participants because the general requirement for graduation from this university is to pass the elementary level of the GEPT.

\section{Procedures}

The study began with the administration of the FLCAS. The participants were reminded that they were not to answer the items based on the specific English task completed but rather on English tasks in general. After all the participants had completed the questionnaire, a 10-item oral listening comprehension test was conducted. Following each item, students answered a multiple choice comprehension question and did a self-rating on the mental effort expended on each item. All of the required data were gathered in person by the authors. To ensure the accuracy of the responses, the authors took the precaution of carefully reviewing the questionnaire's instructions with the participants, so there was no invalid data. 


\section{Results}

Table 1 presents the descriptive statistics of the three variables discussed in this study, that is, foreign language anxiety (FL anxiety), cognitive load, and performance (listening comprehension test scores). Students generally experienced a medium level of FL anxiety and incurred a medium level of cognitive load while taking the listening comprehension test.

Table 1. Descriptive statistics

\begin{tabular}{|c|c|c|c|c|}
\hline & $\mathrm{N}$ & Mean & SD & Range \\
\hline FLCAS & 88 & 2.94 & .404 & $1-5$ \\
\hline CLSRS & 88 & 4.42 & 1.241 & $1-7$ \\
\hline TSLCT & 88 & 4.53 & 1.875 & $0-10$ \\
\hline
\end{tabular}

Note. FLCAS=Foreign Language Classroom Anxiety Scale; CLSRS=Cognitive

Load Subjective Rating Scale; TSLCT=Total Scores of Listening Comprehension Test

Research Question 1 - Does the listening comprehension performance of a foreign language correlate with the levels of FL anxiety and cognitive load?

The results revealed a statistically significant negative correlation between FL anxiety and performance $(\mathrm{r}=-.259, \mathrm{p}<.05)$. Cognitive load was also negatively correlated with performance $(\mathrm{r}=-.483, \mathrm{p}<.01)$. In other words, more anxious students received lower scores in the listening comprehension test; students who had a higher cognitive load also received lower scores in the test.

Research Question 2 - Does the levels of FL anxiety correlate with a learner's cognitive load while engaging in a foreign language listening comprehension task?

The results of the study indicated that there was a positive correlation between FL anxiety and cognitive load $(r=.355, p<.01)$. This means that students with higher FL anxiety also imposed more of a cognitive load on their working memory as they took the listening comprehension test.

Other than the relationships among FL anxiety, cognitive load, and performance, the students' ability levels (lower intermediate or higher elementary) and their perceived difficulty of the listening comprehension task were investigated as well. The results revealed that the students' ability levels were negatively correlated with their FL anxiety $(r=-.236, p<.05)$ but positively correlated with their performance $(r=.287, p<.01)$. This means that students 
at the lower intermediate level were less anxious than those at the higher elementary level. The former also received higher test scores.

Additionally, there was a positive correlation between students' perceived difficulty of listening comprehension and their anxiety level $(r=.425, p<.01)$ as well as the cognitive load $(r=.210, p<.05)$, and there was a negative correlation with their performance $(r=-$ $.284, p<.01)$. In other words, as the degree of the students' perceived difficulty of listening comprehension increased, their anxiety level and cognitive load also increased, while the test scores decreased.

Research Question 3 - Do the levels of cognitive load, FL anxiety, and performance differ across different levels of linguistic ability and perceived difficulty in listening comprehension?

Group differences in anxiety, cognitive load, and performance were examined through independent sample t-tests, in which ability level (higher elementary and lower intermediate) served as the independent variable. Table 2 indicates that there was no significant difference in the cognitive load between higher elementary and lower intermediate participants $(\mathrm{t}=-$ $1.629, \mathrm{p}>.05)$, implying that the cognitive load imposed by the task on the two groups was similar. However, there were notable differences between anxiety $(\mathrm{t}=-2.248, \mathrm{p}<.05)$ and performance in listening comprehension $(\mathrm{t}=2.778, \mathrm{p}<.01)$ between these two groups.

Table 2. Independent t-test of anxiety, cognitive load, and performance between two ability groups

\begin{tabular}{|l|c|c|c|c|c|c|c|}
\hline \multirow{2}{*}{ Variables } & \multicolumn{2}{|c|}{ lower intermediate } & \multicolumn{2}{|c|}{ higher elementary } & \multirow{2}{*}{$t$} & Sig. & $\begin{array}{c}\text { Estimated } \\
\text { effect size }\end{array}$ \\
\cline { 2 - 7 } & Mean & SD & Mean & SD & & .056 \\
\hline Anxiety & 2.83 & .436 & 4.08 & 1.398 & -2.248 & $.027^{*}$ & .056 \\
\hline $\begin{array}{l}\text { Cognitive } \\
\text { load }\end{array}$ & 4.17 & .978 & 3.02 & .362 & -1.629 & .107 & .030 \\
\hline Performance & 5.16 & 2.255 & 4.60 & 1.382 & 2.778 & $.007^{* *}$ & .082 \\
\hline
\end{tabular}

$\mathrm{p}<.05 . \quad{ }^{* * *} \mathrm{p}<.01$.

An analysis of variance (ANOVA) was conducted to examine if the levels of cognitive load, FL anxiety, and performance varied according to the degree of perceived difficulty of listening comprehension (easy, medium, or difficult). The dependent variables were cognitive 
load, FL anxiety, and performance. The results of the analyses are presented in Table 3, which reveal significant differences across the levels of anxiety $(F=11.893, p<.01)$, cognitive load $(F=3.564, p<.05)$, and performance $(F=3.727, p<.05)$ among students with different degrees of perceived difficulty of English listening comprehension.

The Scheffe post hoc test showed that those students who perceived English listening comprehension as medium or difficult reported a significantly higher level of anxiety than those who perceived it to be easy. Similarly, students who perceived listening comprehension as medium or difficult had a higher cognitive load than students who perceived it to be easy.

Table 3. ANOVA of anxiety, cognitive load, and performance for different degrees of PDLC

\begin{tabular}{|c|c|c|c|c|c|c|c|c|c|}
\hline & Variances & SS & df & MS & $\mathrm{F}$ & Sig. & $\begin{array}{l}\text { Estimated } \\
\text { effect size }\end{array}$ & $\begin{array}{l}\text { Post } \\
\text { hoc }\end{array}$ & Sig. \\
\hline \multirow[t]{3}{*}{ Anxiety } & $\begin{array}{l}\text { Between } \\
\text { Groups }\end{array}$ & 3.098 & 2 & 1.549 & 11.893 & $.000^{* *}$ & .219 & $\begin{array}{l}2>1 \\
3>1\end{array}$ & $\begin{array}{l}.001 * \\
.000^{* *}\end{array}$ \\
\hline & $\begin{array}{l}\text { Within } \\
\text { Groups }\end{array}$ & 11.069 & 85 & .130 & & & & & \\
\hline & Total & 14.167 & 87 & & & & & & \\
\hline \multirow[t]{3}{*}{$\begin{array}{l}\text { Cognitive } \\
\text { load }\end{array}$} & $\begin{array}{l}\text { Between } \\
\text { Groups }\end{array}$ & 10.359 & 2 & 5.179 & 3.564 & $.033^{*}$ & .077 & $\begin{array}{l}2>1 \\
3>1\end{array}$ & $\begin{array}{l}.049 * \\
.037 *\end{array}$ \\
\hline & $\begin{array}{l}\text { Within } \\
\text { Groups }\end{array}$ & 123.532 & 85 & 1.453 & & & & & \\
\hline & Total & 133.891 & 87 & & & & & & \\
\hline \multirow[t]{3}{*}{ Performance } & $\begin{array}{l}\text { Between } \\
\text { Groups }\end{array}$ & 24.662 & 2 & 12.331 & 3.727 & $.028^{*}$ & .081 & & \\
\hline & $\begin{array}{l}\text { Within } \\
\text { Groups }\end{array}$ & 281.236 & 85 & 3.309 & & & & & \\
\hline & Total & 305.898 & 87 & & & & & & \\
\hline
\end{tabular}

Note. PDLC $=$ perceived difficulty of listening comprehension. $1=$ easy, $2=$ medium, $3=$ difficult $* \mathrm{p}<.05 . \quad{ }^{* *} \mathrm{p}<.01$.

\section{Discussion and Implications}

In light of the findings of this study, it can be concluded that there is evidence supporting the existence of a relationship between FL anxiety and cognitive load. In addition, it has been found that both variables are negatively correlated with performance; that is, learners with higher level of FL anxiety tend to incur a higher cognitive load in the learning process, and both factors thus interfere with learning. The results confirm Eysenck \& Calvo's (1992) proposal that anxiety causes worry, and worry always impairs performance on tasks requiring high attention or short-term memory. In other words, FL anxiety consumes the working memory's processing resources, leaving less capacity for cognitive tasks. If the task requires a 
large temporary storage capacity, the learning of anxious learners will be impeded. Eysenck \& Calvo's (1992) proposal also explains the positive relationship between learners' perceived difficulty of English listening comprehension and their FL anxiety and cognitive load, as well as its negative relationship with performance. The degree of perceived difficulty causes worry that adds to the level of anxiety and the cognitive load, which in turn adversely affects students' performance. Furthermore, students with higher linguistic ability are less anxious and perform better than students with lower linguistic ability. This finding supports MacIntyre \& Gardner's (1991c) claim that as experience and proficiency increase, anxiety declines in a fairly consistent manner.

The present study also tries to probe another frequently discussed affective factor, that is, FL anxiety. Low \& Sweller (2005) proposed that one way to reduce extraneous cognitive load is to minimize unnecessary demands on the working memory capacity so that cognitive resources can be freed to concentrate on essential activities. From this perspective, one way to reduce cognitive load is to diminish learners' FL anxiety so as to decrease the consumption of the limited, yet precious, working memory resources and devote them to learning tasks. Cognitive load theory has been closely discussed with instructional designing, it is therefore important to take the anxiety factor into consideration when planning instructional procedures or materials for L2 learners.

The positive relationship between FL anxiety and the participant's perceived difficulty of English listening comprehension suggests that by improving learners' perceptions of the difficulty of listening comprehension, their FL anxiety may be reduced. Instructors can perform the role of helping students develop their listening comprehension ability and anxietycoping skills. Researchers have suggested several instructional procedures that help students effectively develop their listening comprehension in foreign languages (Berne, 1998; Elkhafaifi, 2005; Hadley, 2001; Kao, 2006; Rost, 1994):
a) Providing materials that are familiar or relevant to students' interests.
b) Providing materials that are at an appropriate level of difficulty.
c) Conducting pre-listening activities.
d) Providing effective visual aids.
e) Introducing a range of listening inputs, including different types of speakers, speeches, modes of presentations, and situations.
f) Allowing repetition of speech. 
g) Providing support and encouragement to foster confidence in L2 learning.

h) Encouraging learners to independently seek out listening opportunities outside the classroom.

To help learners cope with FL anxiety in a listening class, Elkhafaifi (2005) proposed that instructors assist students to overcome unrealistic expectations about understanding everything they hear. By first being introduced to the gist of the spoken language, students will then gradually become comfortable with grasping the key words when they engage in listening tasks. In this manner, increasing opportunities for learners to experience small successes in the target language will help reduce their FL anxiety.

Although the present study was conducted in the context of English listening comprehension, it is applied to L2 learning in general because the scales used in this study were not specifically designed for English learning only.

\section{Conclusion}

The present study provides some evidence of the role played by FL anxiety and cognitive load in English listening comprehension tasks, with particular emphasis on the relationship between cognitive load and FL anxiety. The findings were consistent with the authors' expectation that learners who experience more anxiety incur a heavier cognitive load and receive lower test scores. To enhance learning effectiveness, instructors are encouraged to identify anxiety-provoking situations and provide a supportive learning environment so that the learners can devote their complete working memory resources to the learning tasks.

This was only a preliminary study on cognitive load and FL anxiety. In the future, a larger sample size, wider range of subjects, and different types of listening comprehension tasks are recommended to validate the current findings. Future research is suggested to answer questions such as "will lengthy listening passages or picture descriptions yield different results?" Besides, since the current study mainly investigated the relationships among cognitive load, FL anxiety, and performance, we were not able to infer the causal relationships among the variables discussed in the study. Thus, it would be of interest to establish a model among these related variables using structural equation modeling to obtain a more comprehensive and deeper understanding of the role that affective factors play in mental activities. 


\section{References}

Baddeley, A. (1992). Working memory. Science, 255(5044), 556-559.

Berne, J. E. (1998). Examining the relationship between L2 listening research, pedagogical theory, and practice. Foreign Language Annals, 31(2), 169-190.

Bratfish, O., Borg, G., \& Dornic, S. (1972). Perceived item-difficulty in three tests of intellectual performance capacity (Technical Report 29). Stockholm, Sweden: Institute of Applied Psychology.

Cooper, G. (1998). Research into cognitive load theory and instructional design at UNSW. Retrieved July 18, 2008 from http://paedpsych.jku.at:4711/LEHRTEXTE/Cooper98.html

Elkhafaifi, H. (2005). Listening comprehension and anxiety in the Arabic language classroom. Modern Language Journal, 89(2), 206-220.

Eysenck, M. (1992). Anxiety: The cognitive perspective. Hillsdale, NJ: Erlbaum.

Eysenck, M. W., \& Calvo, M. G. (1992). Anxiety and performance: The processing efficiency theory. Cognition \& Emotion, 6(6), 409 - 434.

Goh, C. C. (2000). A cognitive perspective on language learners' listening comprehension problems. System 28(1), 55-75.

Hadley, A. O. (2001). Teaching language in context. Boston, MA: Heinle \& Heinle.

Horwitz, E. K. (2001). Language anxiety and achievement. Annual Review of Applied Linguistics 21, 112-126.

Horwitz, E. K., Horwitz, M. B., \& Cope, J. (1986). Foreign language classroom anxiety. Modern Language Journal, 70(2), 125-132.

Kao, C. C. (2006). EFL listening comprehension strategies used by students at the southern Taiwan university of technology. Unpublished doctoral dissertation, University of South Dakota.

Krashen, S. D. (1988). Second language acquisition and second language learning. London: Prentice-Hall International.

Low, R., \& Sweller, J. (2005). The modality principle in multimedia learning (pp.147-158). In R. E. Mayer (Ed.), The Cambridge handbook of multimedia learning. New York, NY: Cambridge University Press.

MacIntyre, P. D., \& Gardner, R. C. (1989). Anxiety and second-language learning: Toward a theoretical clarification. Language Learning, 39, 251-275.

MacIntyre, P. D., \& Gardner, R. C. (1991a). Investigating language class anxiety using the focused essay technique. Modern Language Journal, 75(3), 296-313. 
MacIntyre, P. D., \& Gardner, R. C. (1991b). Language anxiety: Its relationship to other anxieties and to processing in native and second languages. Language Learning, 41(4), 513534.

MacIntyre, P. D., \& Gardner, R. C. (1991c). Methods and results in the study of anxiety and language learning: A review of the literature. Language Learning, 41, 85-117.

MacIntyre, P. D., \& Gardner, R. C. (1994a). The effects of induced anxiety on three stages of cognitive processing in computerized vocabulary learning. Studies in Second Language Acquisition, 16, 1-17.

MacIntyre, P. D., \& Gardner, R. C. (1994b). The subtle effects of language anxiety on cognitive processing in the second language. Language Learning, 44, 283-305.

Mayer, R. E. (Ed.). (2005). The Cambridge handbook of multimedia learning. New York, NY: Cambridge University Press.

Miller, G. A. (1956). The magical number seven, plus or minus two: Some limits on our capacity for processing information. Psychological Review, 63, 81-79.

Osada, N. (2004). Listening comprehension research: A brief review of the past thirty years. Dialogue, 3, 53-66.

Osborne, J. (2006). Gender, stereotype threat, and anxiety: Psychophysiological and cognitive evidence. Electronic Journal of Research in Educational Psychology, 4(1), 109-138.

Paas, F., Renkl, A., \& Sweller, J. (2003). Cognitive load theory and instructional design: Recent developments. Educational Psychologist, 38(1), 1-4.

Paas, F., Van Merriënboer, J. J. G., \& Adam, J. J. (1994). Measurement of cognitive load in instructional research. Perceptual Motor and Skills, 79, 419-430.

Pappamihiel, N. E. (2002). English as a second language students and English language anxiety: Issues in the mainstream classroom. Research in the Teaching of English, 36, 327-355.

Peterson, L., \& Peterson, M. (1959). Short-term retention of individual verbal items. Journal of Experimental Psychology 58, 193-198.

Rost, M. (1994). Introducing listening. London : Penguin.

Sparks, R. L., \& Ganschow, L. (2007). Is the foreign language classroom anxiety scale measuring anxiety or language skills? Foreign Language Annals, 40(2), 260-287.

Sweller, J. (2005). Implications of cognitive load theory for multimedia learning(pp. 19-29). In R. E. Mayer (Ed.), The Cambridge handbook of multimedia learning. New York, NY: Cambridge University Press. 
Sweller, J. (2007). Keynote address: Cognitive load. Paper presented at the Symposium on Cognitive Load: Theory and Applications. Fo Guang University, Yilan, Taiwan.

Sweller, J., Van Merrienboer, J. J. G., \& Paas, F. (1998). Cognitive architecture and instructional design. Educational Psychology Review, 10(3), 251-296.

Tercanlioglu, L. (2005). Pre-service EFL teachers' beliefs about foreign language learning and how they relate to gender. Electronic Journal of Research in Educational Psychology, $3(1), 145-162$.

Van Merriënboer, J. J. G., \& Sweller, J. (2005). Cognitive load theory and complex learning: Recent developments and future directions. Educational Psychology Review, 17(2), 147-177. 
I-Jung Chen et al.

[This page intentionally left blank ] 